\title{
Allelopathic Effects of Chromolaena Odorata L. (R. M. King and Robinson - (Awolowo Plant')) Toxin on Tomatoes (Lycopersicum esculentum Mill)
}

\author{
ONWUGBUTA - ENYI, J. \\ Dpartment of Biology, Rivers State College of Education, P.M.B 5047,Port Harcourt., Nigeria.
}

\begin{abstract}
Allelopathic effects of Chromolaena odorata L. (R. M. KING AND ROBINSON) aqueous leaf extract and residues incorporated in the soil on the growth and water status of Lycopersicon esculentum Mill were studied. Significant growth reductions in Lycopersicon esculentum were observed from additions of $C$. odorata aqueous - leaf extract at concentrations as low as $1 \mathrm{~g}$ fresh weight in $40 \mathrm{ml}$ of water. Reduction in growth was accompanied by decreases in leaf water potential. Incorporation of $C$. odorata leaf material into the soil in which $L$ esculentum Mill seedlings were germinated and grown caused significant depression in growth over the 2-week test period with addition of $2 \mathrm{~g}$ residue to $80 \mathrm{~g}$ soil. Allelochemicals released from $C$. odorata plants and residue are suggested as a possible explanation for yield reductions in crops in fields where $C$. odorata plants are present. One mechanism of toxic action on seedlings involved interference with water balance. @ JASEM
\end{abstract}

Effects of leachates from plants, plant extracts and decomposing plant residues have been the focus of several investigators concerned with the role of allelopathy in agriculture. Plant residues often contain a variety of toxins that are known inhibitors of seed germination or seedling growth (Chov and Patrick. 1976: An, et al 1997). Recycling crop residue to the soil has been reported to be detrimental to future growth (Rice 1981). Leachates from plants have been shown to suppress seed germination and vegetative propagules, and early seedling growth (Babu and Kandasamy, 1997:Dhawan and Gupta, 1996); and decrease radicle growth (Casado, 1995). The extent of damage to the crop is related to the degree of contact of roots to the leachates or residues (Patrick, 1971). Rice et al, (19l81) showed that phytotoxicity from a crop might be from indirect effects of micro-organisms and direct toxic actions. Aqueous extract of some plants inhibit seedling growth (Lydon, et al 1997); root and shoot growth (Athanassova, 1996); germination (Pratley, et al, 1996); and induce mortality of plants (Eyini, et al 1996) .

Schon and Einhellig (1980) demonstrated that incorporation of dried sunflower leaf material into the soil; treatment with aqueous extract, root exudates and leaf leachates inhibited germination and growth of grain sorghum (Sorghum bicolor). Watersoluble toxic substances could leak from the plant and decomposing residue. Allelopathic interference could be mediated through effects on the water metabolism of a crop. Yield losses would occur if Chromoleana odorata toxins reduced the water use efficiency of crops grown in areas of low field moisture. This study examined the effects of aqueous-leaf extracts and leaf residue of $C$. odorata on the growth and water use of Lycopersicon esculentus.

\section{MATERIALS AND METHODS}

Growth of seedlings: Tomato seeds were germinated in germination trays for 4 days. Seedlings were transplanted into plastic pots (7.5 diameter x $15 \mathrm{~cm}$ depth) and grown in a green house. Soil analysis indicated $92.4 \%$ sand, $3.2 \%$ silt and $4.4 \%$ clay, $0.82 \%$ organic carbon, and $1.4 \%$ organic matter with a pHof about 5.2. Compost was added to each pot as noninhibitory organic matter. After 2 days of acclimatization, forty uniform tomato seedlings were selected for each treatment group. These seedlings were treated with Chromolaena odorata leaf extract for 6 days.

Extract Preparation and Treatment: Ten grams of $C$ odorata leaf was extracted in $10 \mathrm{ml}$ of de-ionized water by boiling for 10 minutes and grinding in a blender (Lodhi and Nicijkel, 1973). The extract was filtered through cheesecloth and What man No. 4 filter paper; brought to original volume and added to nutrient media in final ratios of fresh leaf weight to total nutrient of 1:140, 1:80 and 1:40 respectively. The $\mathrm{P}^{\mathrm{H}}$ of the solutions was adjusted to 5.2. Respective seedlings were sprayed with different concentrations (1:40, 1:80 and 1:40) of C. odorata leaves from the seventh day of planting. Spraying was done with a pressure pump diaphragm sprayer once a day.

Parameters: The parameters studied in this study were water potential $(\Psi)$, pressure potential $(\Psi \mathrm{p})$, osmotic potential $(\Psi \pi)$,dry weight of plants and transpiration rate. Osmotic potential $(\Psi \pi)$ was 
measured with vapour pressure osmometer (5500x, Wescor, Logan, U T, USA) calibrated daily with a graded series of $\mathrm{NaCl}$ solution. Four seedlings were used per treatment group to determine the $\Psi \pi$. Youngest leaf of each seedling was punched in two places with a $7 \mathrm{~mm}$ borer to obtain 7 leaf discs. Leaf $\Psi \pi$ was determined with the freeze - rupture technique of Auge, et al (1995). Petri-dishes lined with filter paper on which leaf discs had been arranged were placed on dry ice for 5 minutes. These were allowed to thaw for 10 minutes and then crushed on a filter paper disc. After equilibration in a sample chamber, the $\Psi \pi$ was then determined.

Water potential $(\Psi)$ was measured in a pressure chamber, according to the method of Soldatini, et al (1990). Leaf discs were equilibrated for 2 hours in a pressure - chamber before water potentials were determined. Leaf pressure potential ( $\Psi$ p) was calculated as the difference between $\Psi$ and $\Psi \pi$. shoot and root dry weights were determined using 20 plants from each group after 6 days of treatment. Differences among the dry weights were determined by analysis of variance with Duncan's multiple range test. Data from water parameters were analysed with a t-test. A 6 - day average was also calculated for $\Psi, \Psi \pi$ and $\Psi$ p respectively.

Chromalaena odorata plants were harvested with their leaves and flowers, air-dried and ground using a waring blender. The residue was added to an airdried, silty-clay soil which was sifted mechanically with a sifter of $2 \mathrm{~mm}$ pore size. The leaf residue was mixed with the soil at rates of $0.5,1$, and $2 \mathrm{~g}$ per $80 \mathrm{~g}$ soil, compost manure was added to the control soil. Five tomato seeds were germinated in $80 \mathrm{~g}$ of soil each pot in the green house. Each pot was watered daily to field capacity. Shoot and root dry weights were obtained from 20 plants per group 14 days after planting. Total water use per plant during the growth period after emergence was computed using the method of Soldatini et al (190) and the transpiration ratio (wt:wt) for each test group was determined as the ratio of the average water use (g) per plant to average dry weight (g) per plant. Each series of experiment was duplicated.

\section{RESULTS AND DISCUSSION}

Effects of the aqueous extract of $C$. odorata and residue on the growth of $L$. esculentum Mill.

Aquesous leaf extracts of $C$. odorata reduced the dry weight of tomatoes, the degree of reduction being directly related to the extract concentration (Table 1). Further dilution of the original extract may have effects on the growth of tomatoes since the plants treated with 1:40 extract concentration weighed less than the controls.

Table 1: Effects of Chromolaena odorata aqueous leaf extracts on the growth of Lycopersicon esculentum $L$.

C. odorata
\begin{tabular}{|l|l|l|l|}
\hline Extract & Shoot & Root & Plant \\
\hline Control & $80.1 \pm 3.2^{\mathrm{a}}$ & $33.3 \pm 1.5^{\mathrm{a}}$ & $113.4 \pm 4.7^{\mathrm{a}}$ \\
$1: 140$ & $50.2 \pm 2.0^{\mathrm{a}}$ & $15.0 \pm 1.4^{\mathrm{a}}$ & $65.2 \pm 6.4^{\mathrm{b}}$ \\
$1: 80$ & $38.5 \pm 1.2^{\mathrm{a}}$ & $14.5 \pm 2.0^{\mathrm{a}}$ & $63 \pm 3.2^{\mathrm{b}}$ \\
$1: 40$ & $20.1 \pm 1.9^{\mathrm{b}}$ & $11.7 \pm 1.4^{\mathrm{a}}$ & $31.8 \pm 3.1^{\mathrm{a}}$ \\
\hline
\end{tabular}

Values are the means and SE of 20 seedlings, 6 days after treatment. All values in a column followed by the same letter are not significantly Different. $P<0.05$ according to Duccan's multiple tests.

Table 2: Effects of dried $C$. odorata leave residue in soil on the growth and transpiration rate (TR) of Lycopersicon esculentum

C. odorata
\begin{tabular}{|l|l|l|lc|}
\hline Extract & Shoot & Root & Plant & TR \\
\hline Control & $21.0 \pm 1.5^{\mathrm{a}}$ & $11.3 \pm 0.8^{\mathrm{a}}$ & $32.3 \pm 2.1^{\mathrm{a}}$ & 176 \\
$1: 140$ & $18.4 \pm 1.29^{\mathrm{a}}$ & $09.7 \pm 1.4 \mathrm{bc}$ & $28.1 \pm 6.4^{\mathrm{b}}$ & 176 \\
$1: 80$ & $16.6 \pm 1.3^{\mathrm{a}}$ & $08.8 \pm 0.6^{\mathrm{b}}$ & $25.4 \pm 1.9^{\mathrm{b}}$ & 188 \\
$1: 40$ & $12.2 \pm 0.9$ & $06.4 \pm 0.9^{\mathrm{c}}$ & $18.6 \pm 1.6$ & 193 \\
\hline
\end{tabular}
Values are the means and SE of 20 seedlings, 14 days after planting. All values in a column followed by
the satter are not significantly different. $P<0.05$ according to Duccan's multiple tests.

Many of the tomato leaves treated with 1:40 extract dilution were folded, wilted and showed necrotic spots and scorched leaf tips by the end of the experiment. Some tomato plants of the 1:80 
treatment group developed leaves with marginal burning. Seedlings in all the three treatments showed chlorosis of the youngest leaves and differences in root morphology. Treated tomatoes had shorter, thicker secondary roots than the controls.

Addition of $2 \mathrm{~g}$ of $C$. odorata leave residue to $80 \mathrm{~g}$ of soil significantly reduced the dry weight of tomatoes (Table 2). Effects observed on plant weight were probably from inhibition of both root and shoot growth. Roots were visibly shorter, and some of the shoots had scorched leave tips. Additions of both $0.5 \mathrm{~g}$ and $1.0 \mathrm{~g}$ of $C$. odorata suppressed the weight of tomato plants. C. odorata extracts and residues incorporated in the soil inhibited the growth and reduced the dry weight of tomato plants.

Compost was added to the control soil as a noninhibitory organic matter to maintain organic matter consistency. It is likely that, the suppression of

Table 3: Effects of dried C. odorata aqueous - leaf extract on the water status of Lycopersicon esculentum

\begin{tabular}{|l|l|l|l|l|}
\hline DAYS OF & \multicolumn{4}{l|}{ C. odorata Leaf Weight } \\
\cline { 2 - 5 } TREATMENT & Control & $\mathbf{1 : 4 0}$ & $\mathbf{1 : 8 0}$ & $\mathbf{1 : 4 0}$ \\
\hline $\begin{array}{l}\text { Water Potential }(\Psi) \\
\text { (bars } \pm \text { SE) }\end{array}$ & & & & \\
1 & $-6.4 \pm 3$ & $6.6 \pm 1.0$ & $-6.3 \pm 7$ & $09.2 \pm 1.8$ \\
2 & $-6.1 \pm 9$ & $-4.6 \pm 1.4$ & $6.9 \pm 4$ & $-8.1 \pm 1.6^{*}$ \\
3 & $-6.2 \pm 8$ & $6.0 \pm 1.3$ & $-8.3 \pm 2.8$ & $09.9 \pm 3^{* * *}$ \\
4 & $-4.5 \pm 10$ & $-6.2 \pm 1.0$ & $-8.1 \pm 0.6$ & $-9.9 \pm 1.2^{* *}$ \\
5 & $-4.1 \pm 6$ & $-4.7 \pm 9$ & $-6.5 \pm 1.2$ & $-10.2 \pm 1.5^{* * *}$ \\
6 & $-4.0 \pm 7$ & $-4.3 \pm 9$ & $-8.6 \pm 1.5$ & $-10.0 \pm 1.8^{* * *}$ \\
\hline 6-day mean & $05.2 \pm 3$ & $-5.4 \pm 3$ & $-7.5 \pm 7^{*}$ & $-9.6 \pm 1.2^{* * *}$ \\
\hline
\end{tabular}

Osmotic Potential $(\Psi \pi)(\mathrm{bar} \pm \mathrm{SE})$

\begin{tabular}{|lllll|}
\hline 1 & $-9.3 \pm 7$ & $-8.3 \pm 1.3$ & $-9.3 \pm 7$ & $-10.0 \pm 89$ \\
2 & $-8.5 \pm 1.2$ & $08.6 \pm 4$ & $-12.0 \pm 1.0$ & $-10.2 \pm 3^{*}$ \\
3 & $-8.2 \pm 4$ & $-8.3 \pm 1.1$ & $-10.2 \pm 2$ & $-10.2 \pm 7^{*}$ \\
4 & $-8.9 \pm 1.1$ & $-10.2 \pm 8$ & $-8.8 \pm 5$ & $-12.8 \pm 5^{*}$ \\
5 & $-8.8 \pm 6$ & $-8.6 \pm 8$ & $-8.8 \pm 5$ & $-12.8 \pm 8 * *$ \\
6 & $-9.9 \pm 5$ & $-10.1 \pm 1.0$ & $-4.6 \pm 2$ & $-13.2 \pm 1.5^{*}$ \\
\hline
\end{tabular}

6- day meanpressure potential ( $\psi p)(\mathrm{bar} \pm \mathrm{SE})$ tomato growth in the treatment groups may not be the result of an increase in organic matter but was caused specifically by the presence of $C$. odorata residue. Allelopathic phytotoxins in the residue are a logical explanation for the growth reductions. The concentration - dependent effects observed in growth suppression are characteristic of allelopathic inhibition (Lydon, et al, 1997).

Effects of aqueous extracts and residue on water status of L. esculentum: Although most of plants, it was significantly reduced in treatment (Table 3). Effects on the $\Psi$ ( decrease in both osmotic potential and pressure potential of the plants. 


\begin{tabular}{|c|c|c|c|c|}
\hline 1 & $-2.9 \pm 9$ & $-1.7 \pm 1.2$ & $-3.0+1.1$ & $-0.8 \pm 2.0$ \\
\hline 2 & $2.4 \pm 6$ & $2.0 \pm 1.0$ & $5.1 \pm 1.2$ & $2.1 \pm 1.9$ \\
\hline 3 & $2.0 \pm 1.2$ & $2.3 \pm 1.0$ & $1.9 \pm 2.6$ & $-0.3 \pm 1.7$ \\
\hline 4 & $4.4 \pm 1.1$ & $4.0 \pm 1.0$ & $2.5 \pm 0.6$ & $-1.0 \pm 0.9 *$ \\
\hline 5 & $4.7 \pm 5$ & $3.9 \pm 0.5$ & $2.3 \pm 1.0$ & $-2.6 \pm 1.4^{* *}$ \\
\hline 6 & $5.4 \pm 7$ & $5.8 \pm 1.3$ & $4.0 \pm 2.1$ & $-3.2 \pm 1.6$ \\
\hline $\begin{array}{l}\text { 6-day } \\
\text { mean }\end{array}$ & $2.9 \pm 5$ & $3.7 \pm 0.5$ & $2.1 \pm 0.7$ & $-8.6 \pm 0.8^{* *}$ \\
\hline \multicolumn{5}{|c|}{ Values are means and SE of 8 seedlings. } \\
\hline
\end{tabular}

Table 4: Effects of dried C. odorata in soil on the water potential ( $\psi$ bars) of Lycopersicon esculentum

\begin{tabular}{|l|l|l|l|l|}
\hline \multirow{2}{*}{$\begin{array}{l}\text { Days of } \\
\text { treatment }\end{array}$} & \multicolumn{4}{|l|}{ Addition of residue to 80g soil } \\
\cline { 2 - 5 } & Control & 0.5 & 1.0 & 2.0 \\
\hline 9 & $-3.9 \pm 1.3$ & $-3.6 \pm 1.7$ & $-4.3 \pm 0.9$ & $-5.9 \pm 1.3$ \\
\hline 12 & $-3.2 \pm 1.0$ & $-4.0 \pm 1.0$ & $-4.4 \pm 1.1$ & $-4.8 \pm 15$ \\
\hline 14 & $-4.5 \pm 2.2$ & $-4.4 \pm 1.3$ & $-4.3 \pm 1.0$ & $-5.9 \pm 2.1$ \\
\hline
\end{tabular}

Values are the means and SE of 8 seedlings

Total water use was reduced in all treatment groups although transpiration ratio was consistently affected (Table 3). Tomato plants grown in $2 \mathrm{~g}$ amendments had $\psi$ values 1.5 to 4.8 bars lower than control plants (Table 3). However, they were not statistically different from $t$ he controls. The data shows that inhibition of the growth of tomato plants was generally related to changes in the plants water status. Tomato plans inhibited by the $2 \mathrm{~g}$ of $C$. odorata residue in the soil showed a trend toward lower leaf $\psi$, but it was not as marked as in the extract experiments. It is not certain whether interference with water balance and water metabolism is the only, or even the primary mode of action of phytotoxic substances from C. ododrata. However, it is reasonable that any effect on water utilization would interfer with growth. Cotton and Einhellig (1980) reported that soyabean seedlings inhibited by aqueous velvet leaf (Abuliton theophrasli Medic.) extracts had decreased $\psi$, and reduced water content. Such effects on water balance may result from the action of known allelochemical that are coumarin or phenolic acid derivatives. Patterson (1981) had reported that t-cinnamic, p-coumaric, vanillic, caffeic, and gallic acids respectively severely reduced photosynthetic rate in soyabeans (Glycine max L.). Soyabeans treated with caffeic, and gallic acids had a significant depression of leaf. It is possible that the allelochemicals effects of $C$. odorata noted in this experiment are caused by phenolic acids and related allelochemicals. Our data indicate that the mechanisms of toxic action involve interference with water balance in the seedlings. These effects may be magnified when water availability is a critical factor in a field situation.

Presence of $C$. odorata in a field may result in the accumulation of leachates and residues that are toxic to crops, resulting in yield losses. It is therefore important that $C$. odorata be removed as early as they germinate in a farmland where tomato plants are grown.

\section{REFERENCES}

An, M., Pratley , J. E., T., Jellett, P.(1997). Genotypic variation of plant species to the allelopathic effects of vulpia residues. Australia - Journal of Experimental -Agriculture 37:6; 647-660.

Athanassova, D. P., (1996). Allelopathic effect of Amaranthus retroflexus $L$. on weeds and crops. Seisieme Conterence du columa. Journees Internationales $\mathrm{Sr}$ La Luttr contre les mauviases herbs, Reims, France. 437-442.

Auge, R. M.,stodola, A. . W., Ebel R.C., Duanm, (1995). Leaf elongation and water relations of mycorrhizal sorghum in response to partial soil drying: two Glomus species at varying phosphorus fertilization. Journal of experimental Botany col:46, No.284,297-307.

Babu, C. M., Kandasanmy, O. S., (1997). Allelopathic effects of Eucalyptus globulus Labill.on Cyperus rotundus L. and Cynodon 
dactylon L. pers. Journal of Agronomy and crop science 179,2, $123-126$.

Casado, C. M., (1995). Allelopathic effect of Lantana camara (Verbenaceae) on morning glory (Ipomoea tricolor) Rhodora, 97:891, 264 $-274$.

Chov, C.H., Patrick, Z. A., (1976). Identification and phytotoxic activity of compounds produced during decomposition of corn and rye residue in the soil. J. Chem Ecol. 3, 365 367.

Cotton, C. E., Eunhellig, F. A., (1980). Allelopathic mechanisms of velvet leaf (Abutilon theophrastic, medic, Malvaccac) on soyabean. Amer. J. Bot. 67: 1407 - 1412

Dhwan, S. R. Gupta, S. K. (1996). Allelopathic potential of various leachate combinations towards SG and ESG of Parthenium hysterophorus Linn. World - Weeds 3:1, 85 88.

Eyini, M., Maheswari, A U., Chandra, T., Jayakumar - M., (1996). Allelopathic effects of leguminous plants leaf extracts on some weeds and corn. Allelopathy Journal 3:1, 85 - 88.

Lodhi, M. A. K., Nickell., G. L. (1973). Effects of leaf extracts of Celtis laevigata on growth, water content and carbon dioxide exchange rates of three grass species. Bule. Torrey Bot. Club 100: 159 - 165.
Lydon, J., Teasdale, J. R., Chen, P. K., (1997). Allelopathic activity of annual wormwood (Artemisia annual and the role of artemisinin. Weed Science 45:6 807 - 811.

Rice, E. L., C. Y., Haung, c. Y., (1981). Effects of decomposing rice straw on growth of and nitrogen fixation of Rhizobium. J. Chem. Ecol. 7: 333 - 344.

Patrick, Z. A., (1971). Phytotoxic substances associated with the decomposition in soil of plant residues. Soil Sc. III: $13-18$.

Pratley, J. E., Dowling, P., Medd, R., (1996). Allelopathy in annual grasses. Wild oats, annual ryegrass and vulpia. Proceedings of a workshop held at Orange, New South Wales, Australia 1: 213 - 214.

Patterson, D. T., (1981). Effects of allelopathic chemicals on growth and physiological responses of soyabean (Glycine max) Weed Sci. 29:309-326.

Schon, M. K. and Einhellig, F. A., (1982). Allelopathic effects of cultivated sunflower on grain Sorghum. Bot. Gaz. 143: 505-510.

Soldatini, G. F., Ranieri, A., Gerini, O., (1990). Water balance and photosynthesis in Zea mays $L$. seedlings exposed to Drought and Flooding stress. Biochem. Physoil. Pflanzen 186, $145-152$. 